\section{Eating Your Words: Discursive Psychology and the Reconstruction of Eating Practices}

SALLY WIGGINS, JONATHAN POTTER, \& AIMEE WILDSMITH

L oughborough U niversity, UK

SA L LY WIG G IN S has a degree in psychology from the $U$ niversity of $D$ undee. She is currently carrying out doctoral research at $L$ oughborough $U$ niversity on eating practices and food evaluations.

J ONATHAN POTTER is Professor of Discourse $A$ nalysis at $L$ oughborough $U$ niversity. $\mathrm{H}$ is main research interests are in theoretical, metatheoretical and methodological features of discursive psychology. $\mathrm{H}$ is most recent book is R epresenting R eality (L ondon: Sage, 1996).

A IMEE WILDSMITH has a degree in social psychology from L oughborough $U$ niversity. She is currently carrying out doctoral research on eating and eating disorders.
A C K N O W LE D GEMENTS. The authors would like to thank Jackie A bell, Wendy Stainton R ogers and Carla Willig for their helpful comments on an earlier draft of the article.

COMPETING INTERESTS: None declared.

A D DRESS. Correspondence should be directed to:

SA LLY WIG GIN S, D iscourse and R hetoric G roup, D epartment of Social Sciences, L oughborough U niversity, L oughborough, L eicestershire, LE 11 3TU, UK

[Tel. 01509 228870; Fax 01509 223944; email: S.K.W iggins@lboro.ac.uk]
Journal of $\mathrm{H}$ ealth Psychology

Copyright (c) 2001 SA GE Publications

L ondon, Thousand $\mathrm{O}$ aks and N ew D elhi, [1359-1053(200101)6:1]

Vol 6(1) 5-15; 015308

\section{Abstract}

Psychological research into eating practices has focused mainly on attitudes and behaviour towards food, and disorders of eating. $U$ sing experimental and questionnaire-based designs, these studies place an emphasis on individual consumption and cognitive appraisal, overlooking the interactive context in which food is eaten. The current article examines eating practices in a more naturalistic environment, using mealtime conversations tape-recorded by families at home. The empirical data highlight three issues concerning the discursive construction of eating practices, which raise problems for the existing methodologies. These are: (1) how the nature and evaluation of food are negotiable qualities; (2) the use of participants' physiological states as rhetorical devices; and (3) the variable construction of norms of eating practices. The article thus challenges some key assumptions in the dominant literature and indicates the virtues of an approach to eating practices using interactionally based methodologies.

\section{Keywords}

conversation analysis, discourse analysis, discursive psychology, food and eating, methodology, rhetoric 
THE FIELD of food and eating research has expanded rapidly in recent decades, particularly in relation to health, and embodied identities (e.g. Hill \& Franklin, 1998; Lupton, 1996; $M$ alson, 1998). The vibrancy and variety of such work is due in part to the range of psychological and sociological approaches adopted and the use of established methodologies. In this article, the focus is on the dominant psychological approach, which concentrates on the cognitive and behavioural aspects of an individual's eating behaviour (e.g. Mizes \& Christiano, 1995; R odin, 1990). W hile this perspective has greatly influenced eating research, it will be argued that the use of individual methodologies has prevented an examination of the interactional nature of eating (though see 0 chs, Pontecorvo, \& Fasulo, 1996, for developments in this area). By using empirical examples, the current article aims to highlight certain phenomena that appear to be absent in research using experimental methods, and thus illustrate potential problems with current methodologies. It is to be argued that these instances raise issues that are fundamental to research on eating practices.

To begin with, we provide a broad overview of the main topics of eating research and the assumptions embedded within the methodological framework. These topics can be classed as follows: consumption behaviour; attitudes and taste preferences; and the links between eating and body image. Each type of research is typically based on experimental, cognitive or clinical methods, which place an emphasis on individual behaviour (e.g. B olles, 1990; R olls \& H etherington, 1990; Wardle, 1995; Williamson, B arker, Bertman, \& Gleaves, 1995). We now consider these topics in turn.

\section{Consumption behaviour}

This first type of study involves participants consuming foods in a controlled environment and completing rating scales concerning the food and their perception of physiological and cognitive states (e.g. R odin, 1990; Wardle \& B eales, 1988). This approach is concerned with the means by which food cues are perceived, experienced and cognitively appraised by the individual (see R odin, 1990, for a brief review). For example, Wardle and Beales (1988) tested the effect of eating a 'preload' amount of food on the subsequent eating behaviour of dieters and non-dieters. This type of research suggests that the physiological effects of different foods and the cognitive appraisal of eating behaviours are primary concerns of the research. For example, participants may be asked to taste a food and then indicate on a rating scale the extent to which they feel full, or satiated (e.g. Rolls \& Hetherington, 1990). M easures such as these may then be used to give an indication of an individual's eating habits, and his or her attitudes toward particular foods (e.g. R ogers \& Blundell, 1990).

The implicit assumptions within this type of research can be summarized as follows:

- Physiological states are accessible through quantifiable, external measures

- E ach measurement is taken to be an accurate representation of an internal state

- Participant responses are treated as being related to, and therefore predictors of, actual eating behaviours.

\section{Attitudes and taste preferences}

Similar assumptions are present in studies that seek to assess attitudes or preferences that people may have towards foods (e.g. Clarke $\&$ Palmer, 1983; O gden \& Thomas, 1999). The aim of this type of research is often to educate people into 'healthier' eating habits, or to determine why people have particular attitudes towards different foods (N ash, 1990; R ogers \& B lundell, 1990). M ethods used for this type of research typically draw on questionnaire or rating-scale designs, in which food tasting may or may not be a component. For example, $\mathrm{O}$ gden and Chanana (1998) used questionnaires to determine the relationship between ethnicity and weight concern, with respect to beliefs about food and eating. The assumptions implicit within attitude research are therefore that:

- Individuals possess a fixed attitude towards food/eating, based on an internal, cognitive state

- Use of appropriate methods will provide access to such attitudes, and to participants' 'true', underlying beliefs

- Attitudes are the result of individual appraisal, preferences and motivations. 


\section{Eating and body image}

The third main topic of eating research is based on the individual's perception of his or her body image, and the links that this may have with eating behaviour and its disorders (e.g. Heatherton, Herman, Polivy, K ing, \& M cG ree, 1988; Mizes \& Christiano, 1995). For example, Hill and Franklin (1998) used rating scales and body image diagrams to determine the dieting beliefs and behaviours of daughters and their mothers, and the transmission of food values. Studies of this kind typically categorize participants as 'dieters' or 'non-dieters', in an attempt to examine the processes of 'restraint' that are thought to pervade dieters' lifestyles (e.g. Kennett \& Nisbet, 1998; Stunkard \& M essick, 1985; Wardle \& B eales, 1988).

The measurement of eating attitudes is often based on participants' questionnaire responses, and the distinction made between 'restrained' and 'unrestrained' eaters is predominantly defined as being the midpoint of the response distribution (Herman \& Polivy, 1980). U se is made of pictorial body image diagrams, in order to determine participants' perception of their appearance (e.g. M onteath \& M cCabe, 1997). This type of research therefore assumes that:

- Eating behaviour can be characterized as 'restrained' or 'unrestrained' using appropriate measures

- Participants' body image is based on perceptual and cognitive processes, and these can be represented pictorially

- Participant responses are representative of internal states and are independent of other individuals.

The common assumptions of the three types of eating research can be summarized as follows: eating behaviour is treated as an individual activity involving perceptual and cognitive appraisals which directly influence eating styles; quantifiable measurements can be used to access internal states and thus predict eating behaviour; and participant responses are truthful and representative of internal states.

$\mathrm{H}$ aving outlined briefly some of the assumptions of existing research on eating, we will now consider an alternative approach to eating practices. The current article examines the interactional nature of eating practices in everyday contexts. So rather than looking at individual consumption, the emphasis is on studying eating practices as they occur in the context of social interaction. This has involved the collection of empirical data from more 'naturalistic' environments, in the form of mealtime conversations. A discursive, social constructionist approach is adopted (e.g. Billig, 1987; Edwards, 1997; E dwards \& Potter, 1993; Potter, 1996; Potter \& Wetherell, 1987). The aim is to examine the constructive nature of discourses concerned with food and eating, and the ways in which these are used to build identities in interaction. A $n$ examination of the data highlighted certain phenomena, which receive little emphasis in the current literature. It is worth repeating at this stage that the emphasis here is on using these instances simply to question dominant assumptions. They can be broken down into three themes, each of which is concerned with the construction of an aspect of eating:

1. The object of eating; the food itself. $\mathrm{H}$ ow can the nature of food be flexibly built up and transformed?

2. The participants' physiology (e.g. state of hunger). How can this be constructed and rhetorically deployed in interaction?

3. The practice of eating, and the notion of 'restraint'. How can restraint (or lack of restraint) be manufactured in sequences of interaction in ways which account for, and justify, different activities?

\section{Method}

\section{Materials and participants}

Tape-recorded conversations from family mealtimes were used as the data for this study. Three families were recruited via non-academic personal contacts to record the conversations themselves using a portable tape-recorder. R ecording was carried out over a seven-day period for each family, in order for the participants to become acclimatized to the equipment. The full corpus is over 15 hours of recorded conversation.

Families with adolescent daughters were chosen to allow for easier access to 'eating' talk, as adolescence was deemed to be a period when socialization into food and eating habits often occurs (see Davies \& Furnham, 1986; O chs, Pontecorvo, \& Fasulo, 1996). Additionally, 
female adolescents are often the focus of concerns about eating and dietary behaviour (Grogan \& Wainwright, 1996; Hill \& Franklin, 1998), so it seemed appropriate to consider daughters in particular.

The tapes were all transcribed to a 'first pass' level that captured the words used and some basic features of the delivery of talk. Passages of interaction that involved talk about food, and negotiations of what to eat or not to eat, were transcribed more fully using the scheme developed by $\mathrm{G}$ ail J efferson (see A ppendix for transcription notation).

\section{Analytic procedure}

The analytic approach is derived from discursive psychology and conversation analysis ( $E$ dwards \& Potter, 1992; Hutchby \& Wooffitt, 1998; Potter, 1997, 1998). The data corpuswas examined with a concern for the constructive and actionorientated nature of the participants' talk; how the participants themselves made sense of, and orientated towards, each other's utterances. Notes were made during the transcription process, and during further readings of transcript and listenings to the tape. Of particular interest were points where the material seemed to depart from assumptions about eating in the standard literature. These points were discussed between the authors and in data sessions with researchers working on other materials. Three issues were raised that highlighted potential limitations with previous research. For this article a small number of extracts were selected from the larger corpus of data, on the basis that they illustrated these limitations. Extracts from one family were chosen to simplify the exposition.

\section{Analysis and discussion}

We will examine three issues in detail: (1) construction of the object; (2) construction of the individual; and (3) construction of the behaviour. Each issue relates to the discursive construction of eating practices within interaction.

\section{Issue 1: Constructing the} object-food

Sociological literature on food and eating has highlighted the importance of the structure of mealtimes and the interactional meanings associated with food on such occasions (e.g. Douglas \& Nicod, 1974; Goode, Curtis, \& Theophano, 1984; Otnes, 1991). In relation to this, our first data example is taken from near the end of a family mealtime, in which Sue, the mother, begins to clear away the dinner plates. A Iso present are her two daughters, Chloe and E mily, who are in their early teenage years. The extract begins immediately following a conversation about decorating the house.

\section{Extract 1: SKW/Ala/M1}

1 Sue: $>$ Come on $<$ there was only a Ttiny bit of (.) of

2

$\downarrow$ salmon just $\uparrow$ ea:t salmon

3 Chloe: $\uparrow N: \underline{o}$ its fo:ul

4

5 Emily: I've eaten $\uparrow$ mine

6 Sue: Ye:ah $\uparrow$ you've eaten $\downarrow$ yours

7

8 Chloe: I've been try:ing but (mine's inedible)

The first point highlighted by this fragment of conversation is that the family membershere are not abstractly consuming foods as individualstheir mealtime is an interactive event, where there is a strong sense of involvement with each other's actions. Similarly, there are related activities taking place within the talk, such as urging, offering, and negotiating consumption. Such activities are a part of everyday conversation and interaction (E dwards, 1997) and in this instance they become bound up with the practice of eating. For example, Chloe's mother encourages her to eat the salmon (lines 1-2), which Chloe resists by stating that the salmon is 'fo:ul' (line 3). Constructing the food in this way-as being unpleasant-allows Chloe to provide an account for why she is not eating her food. E ating, or not eating, is seen here as something for which $\mathrm{C}$ hloe is being held accountable.

So, not only are there negotiations within the interaction, but these are also bound up with the construction of the food. In giving reasons for eating or not eating the food, its nature is simultaneously constructed and evaluated. O ne way in which descriptions can be evaluative is to offer a particular representation of the object at 
the expense of all others; i.e. they implicitly argue against other (potential) descriptions (Billig, 1987; Potter, 1996). Therefore, it is not only the act of eating that is being negotiated, but also the nature of the food itself. How one describes the food is related to how the food will then be treated, for example, whether it will be classed as something that one should, or could, eat.

Negotiating about the nature of food is thus a continuous process, requiring the joint efforts of the individuals involved. Each turn of talk can serve to give a new definition, and therefore construction, of the food or activity. In E xtract 1, for example, E mily's utterance 'I've eaten Tmine' (line 5), contrasts with Chloe's construction ('its fo:ul'; line 3), through its sequential position in the conversation. By stating that she was able to eat the food, Emily's talk redefines it as being edible. We can confirm this interpretation of the interaction by looking at the next turn in the conversation, in which Sue repeats Emily's statement as if suggesting that it supported her argument (line 6). This orientation demonstrates that it was treated as a reconstruction of the food as edible, rather than foul; hence the 'problem' lies with Chloe, and not the food.

A further example of the construction of food can be seen in the next extract of conversation below. This section is taken from near the start of a family mealtime, and involves a brief exchange between the father, $M$ ark, and his daughter Chloe. It follows a lull in the conversation, before Chloe makes a comment about the meal itself.

\section{Extract 2: SKW/Ala/M2}

1 Chloe: There's $>\uparrow$ so much<tu:na in Mum

2

3 Mark: It's $\uparrow$ ni:ce (0.4) it's-it's: tuna pasta (0.4)

4 that's why there's so much tuna >in it<

$5 \quad(4.0)$

6 Chloe: IIt's $<$ tuna with pasta (0.2) not pasta with

7 tuna>

This extract differs from the first in that there is no direct negotiation about eating the food, but rather a negotiation over how the food may be defined. By using different expressions and emphases in their talk, the speakers are able to construct the food in quite different ways. This simple, yet powerful, use of discourse demonstrates how evaluations may be made about food through what seem to be merely observational comments. For example, by stating that: 'There's $>\uparrow$ so much< tu:na in Mum' (line 1), Chloe not only presents a description of the food, she also displays an orientation to it in a particular way; in this context 'so much' is hearable as 'too much'. By looking now at the other speaker, Mark, we can see how he constructs the food differently, and simultaneously offers a more positive evaluation. In other words, the meal is defined as being 'nice' (line 3 ), and as containing a lot of tuna for a good reason (i.e. it's a tuna dish). D escribing the food as being either 'tuna with pasta', or 'pasta with tuna' (lines 6 and 7) sets up a particular evaluative construction of the food.

We have seen, therefore, that food (as any other object) can be negotiated, defined and constructed in talk, and that this is an ongoing, jointly achieved process. In contrast, previous studies have tended to treat food as an object to be individually appraised, and responded tothrough eating it, or not eating it. However, if constructions of food may be variable, and produced in interaction, this raises problems with the assumptions highlighted earlier. U sing an experimental methodology, which requires participants to give a unitary response on a particular variable (e.g. niceness), places constraints on the way in which the food may be constructed. What has been overlooked is the fluidity and scope of food construction. Predefining the nature of food restricts this practice, and alters the meaning of both the food and its consumption.

\section{Issue 2: Constructing the individual-physiology}

Let us now consider what psychologists would typically conceptualize as the physiological dimensions of eating; that is, phenomena such as hunger, satiety and taste. Our focus, again, is with the way these things are constructed in talk.

The following fragment of conversation is taken from another mealtime, about halfway 
through the meal. Mark, the father, is clearing away the dinner plates, when the conversation turns to the food left on his daughter's (Chloe's) plate. A Iso present are E mily, the other daughter, and their mother, Sue (who does not speak in this extract).

\section{Extract 3: SKW/A2a/M5}

1 Mark: $\uparrow W h: y \downarrow d o n ' t$ you want this Chlo e?

2

3 Chloe: 이'm $\uparrow f u: I^{\circ}$

4

5 Mark: $\uparrow \underline{W}$ hy are you always full you $\downarrow$ two

7 Mark: I ca:n't underst:and at $\downarrow$ your a $[\mathrm{ge}().\rceil \mathrm{I}$

8 Emily: Łna-」

9 M ark: used to be eat $\downarrow$ ing,

10 E mily: $H$ aven't got very big $\uparrow a p p e t i t e s=$

11 Chloe: $=E-\uparrow E m m i e ' s$ no:t (.) tha:::t (0.8) $\downarrow$ f:ull all the time but my=

13 Mark: =B ut you keep ea:ting things in 14 be $\lceil$ twe:e $\rceil n \uparrow$ meals

15 Chloe: \Look」

16 Chloe: $\downarrow$ M um (.) can you tell him my appe $\downarrow$ tites gone

19 E mily: 'Y ou've just said it ${ }^{\circ}$ 20 (1.8)

21 Chloe: >No but< she's been $\downarrow$ here so she can

22 个pro:ve it

A s before, this extract illustrates an account of food which is jointly produced. In this case, the conversation is concerned with Chloe's physiological state-how full she feels. Simply stating that she is full (line 3 ) is not, on this occasion at least, treated as adequate as a reason for her failing to eat all of her meal. $U$ pon being questioned by her father, Chloe then goes on to produce a more elaborate account of her internal state using references to appetite and the presence of others to achieve this.

R eporting one's physiological state can therefore involve more than describing internal sensations, which is the assumption in many psychological studies (e.g. Birch, 1990; R ogers \& Blundell, 1990). H ere we have seen an instance where some further formulation is required, and in particular some report of evidence, in order for the report to be treated as an acceptable account. In this respect, physiological states are treated as negotiable. For example, M ark (line 5) starts to treat his daughters' fullness as a move in an argument. $Y$ et an internal sensation, such as fullness or taste preference, is generally regarded in current research as something purely individual. What is being suggested here is that in practical situations such 'states' can be open to public discussion; that is, they can be negotiated, disputed and argued for or against. Descriptions of one's physiological state, then, are not simply descriptions, but resources within interaction, available to all participants. Physiological accounts can be used to answer questions, requests, or to justify behaviour; to treat them as merely representational would be to underestimate their orientation to action.

L et us illustrate this by contrasting the way a physiological state can be constructed in a conversation with how it is defined in a consumption questionnaire. For example, constructing 'hunger', or 'satiety', as unitary physiological states in experimental terms may underestimate the variety of ways in which these sensations can be evoked in everyday discourse ( see L upton, 1996, p. 33). Talking about being 'full', in Extract 3, provided $\mathrm{Chloe}$ with an account or justification for a particular course of action (i.e. not eating all of her food). The use of questionnaires and rating scales may obscure the flexibility around the meanings of physiological accounts. U sing an approach which can deal systematically with natural discourse is one way to reveal these flexible constructions.

O ur next example takes another 'physiological state'-taste-and shows how it is variably constructed in interaction. Extract 4, below, is taken from near the end of a family mealtime, 
with the same family members as in the previous examples. Once again, as the plates are cleared away, attention turns to what has, or has not, been eaten by the daughters.

\section{Extract 4: SKW/A1b/M4}

1 E mily: I've $\uparrow$ only left the vegeta $\downarrow$ bl:es

2 Mark: ${ }^{\circ}$ Well ${ }^{\circ}$ I want you to eat the 个vegetables:

3 that's the wholle point

4 Chloe: Lmmmrrrr $\downarrow$ gghhhhhh 5

6 Mark: 「(have a bit of chicken)

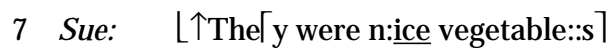

8 Emily: L<Com:e $\downarrow$ on $\underline{C h l:: o e>=}$

9 M ark: $=$ They're $\uparrow$ lovely they $\downarrow$ were (.) they were

10 co:oked in the $\uparrow$ wok (.) they weren't b:oiled

11 or anything like $\downarrow$ that

This section of conversation provides an illustration of how taste can be constructed as being an objective quality of food. $M$ ark speaks about the vegetables as being 'n:ice' (line 7) and ' lovely' (line 9), as if this was how they really are, regardless of individual tastes. By depicting them in this way, an argument is produced as to why E mily should be eating them. The 'point' of eating appears to be negotiated in terms of quantity and quality. E mily claims that she has eaten most of her dinner, leaving 'only' the vegetables (therefore emphasizing the quantity eaten). $M$ ark then replies to this by stating that the 'whole point' (line 3) of eating the meal is to eat the vegetables, thus stressing the type of food to be eaten (with the emphasis on the quality). The quality of the food is further emphasized in lines 9-11, in which the method of cooking is used by Mark to account for how 'lovely' they were (line 9). This offers the construction that one's sensory experience of the food is dependent on external, rather than internal factors.

What we have tried to show here are the ways in which attitudes and preferences about foods are more complex than is suggested in much current research, and that there is more to physiological accounts than the representation of individual sensations. The analytic examples discussed here suggest that these apparently fixed states can be used both flexibly and rhetorically in interaction. This sharply contrasts with results found in experimental situationsperhaps because of the presence of others, but more importantly, by the way in which the 'attitude' itself is regarded. Constructing evaluations is an activity that participants accomplish themselves- they are not just passively responding to internal, cognitive or physiological states (Potter \& Wetherell, 1987).

\section{Issue 3: Constructing the \\ behaviour-refusing food}

The final issue is concerned with the way eating practices are categorized as 'normal' or 'restrained' (e.g. Herman \& Polivy, 1980). A s discussed in the introduction, this is often based on questionnaire responses about behaviour and attitudes to wards food, and places constraints on the way in which the behaviour may be defined by the participants themselves. We now consider an extract of conversation in which such an issue arises. This extract was taken from near the start of a family mealtime, in which Sue (the mother) asks Chloe (her daughter) about her day at school.

\section{Extract 5: SKW/A1a/M2}

1 Sue: $\quad$ What $>$ did you $<$ have for $\uparrow$ lunch t'day?

$2 \quad(2.0)$

3 Chloe: I had a chi:cken pi::e.

4 (3.0)

5 Chloe: (2 syllables) $=$

6 Mark: $=\mathrm{A} \mathrm{n}^{\prime}$ what

7 Chloe: A choc:olate do:ughnut ((smiley voice))

8 Sue: I heard $\lceil$ you (.) sha:med your $\downarrow$ self.

9 Mark: LFor $\uparrow$ lunch

10 Chloe: $\downarrow \underline{\text { No }}$ but I $\uparrow$ didn't have any $\downarrow$ break I came in

11 and ev'rybody was hh buying like (.) pizzas 
12

13 and a-a slice of pi:zza and a (.) a cho:colate (.) e:r sli::ce for break =

14 Mark: =For break=

15 Chloe: =A nd then $\lceil$ for $\rceil$ lunch they have like a (0.2) a-

16 Mark: $\lfloor A: h\rfloor$

17 Chloe: ânother piece of pizza and a(0.2) an' a(.) chocolate slice and ${ }^{\circ} \uparrow$ two lunches $>$ in one day< I $\lceil$ mea $\rceil n$ (.) even when I 个am (.) li:ke

20 Mark: \mm」

21 Chloe: (0.2) my <pi:ggy self $>(0.2)$ don't eat $\uparrow$ that

22 mu:ch

A s in the other extracts, what we can see here is the production of an account-in this case it is an account of what was eaten by $\mathrm{Chloe}$, and others, at school that day. Through describing the food in a particular way, Chloe is able to construct a definition of what is 'normal' in this situation. For example, in using expressions such as 'everybody' (line 11) and 'they have like' (line 15), she displays such eating practices as being general, frequently occurring activities (see Pomerantz, 1986, and E dwards, 2000, for how such expressions can be used to 'normalize' accounts). The constructive element of talk, then, offers a means of defining both the behaviour of self and of others. This has a rhetorical function in that one can portray a particular version of events in a way that justifies one's actions (Potter, 1996). In the extract above, Chloe is able to account for her own behaviour (eating the doughnut) through comparing her actions to those of others. By producing an account of what is 'normal' she can then construct her own actions as being somewhat restrained in comparison, and thus defend her behaviour against criticism (see Edwards, 1994; Smith, 1978, on the construction of normalizing accounts).

O ur final data example further illustrates the rhetorical nature of talk, with respect to the eating habits of others. The following section of conversation is taken from the middle of a family mealtime, in which Chloe is referring to friends of hers at school. The discussion from which it is taken centres around how much food other people eat, and how this may relate to their body shape.

\section{Extract 6: SKW/A1a/M2}

1 Chloe: <She $\uparrow$ does (0.6) she does: (0.6) she

2 does eat a lo:t (0.2) but the:n (.) so

3 does Ja:ne>

4 Mark: Well Lane doesn't-

5 Sue: $\uparrow$ Jane doesn't $\uparrow d: 0$ anything

6 Chloe: No but-

7 Sue: (Or) play spo:rt

8 Chloe: I know but 」ane ea:ts: a lo:t

In this sequence, an individual's eating habits is defined using a reference to, or comparison with, those of another person. The notion of eating a lot of food (as in lines 1 and 2) is given meaning through being defined as a relative quality. As was indicated earlier, what may be seen as restrained requires a 'normal' level with which to compare it. In this instance, what may be seen as excessive also requires a sense of what is to be expected from others. This is similarly bound up with notions of sport and activity in relation to eating habits. Jane is described as eating a lot, despite being inactive (lines 4-7), suggesting that this is not the 'norm' in this situation. The construction of others' behaviour is hereby defined as being dependent on a comparative source.

The above extract also highlights the issue of accountability in relation to eating habits. A s in Extract 5, in which Chloe was held accountable for eating a doughnut, in this latter extract it is Jane whose behaviour is under debate. Her eating habits are being assessed in relation to her physical activity rather than simply her physiological state. This idea of being held accountable for what one eats is an important aspect of interaction, particularly in relation to body image and the 'thin ideal' (Davies \& Furnham, 1986; G rogan and Wainwright, 1996). In Z drodowksi's (1996) paper, for example, she noted how the eating behaviour of women classed as 
'overweight' was always accounted for in terms of their size. I $f$ they ate a lot, they were 'greedy', and so it was no surprise that they were 'fat'. Conversely, though, if they ate only a little, it was because they were on a diet-due to their size. Similarly, Wetherell (1996) found that teenage girls talked about body image and eating in terms of accountability, and that connections were made pervasively between the foods eaten and body size. $R$ ather than being fixed, though, these accounts were variable, and the girls drew on different repertoires as the rhetorical context altered. This latter study also suggests that using a discursive framework may open up new avenues of research in this area.

There is therefore more to the notion of 'restraint', or refusing food, than is suggested by the questionnaire designs typically used in current research. It can be used as a resource in interaction, to account for, justify and explain behaviours-both one's own, and those of others. 'N orms' of eating are often constructed in relation to restricted eating practices, though these are often used retrospectively in accounts rather than existing to predetermine the behaviour (e.g. Herman \& Polivy, 1980). A s an example of constructing norms, Beach (1996) demonstrated how an individual with bulimia nervosa constructed her behaviour as 'normal' by developing descriptions which invoked social norms and everyday events in particular ways. M alson (1998) also argued this point in her study of the discourses of anorexia nervosa, which highlighted the rhetorical and subjective nature of accounts of eating behaviour. B oth of these studies have illustrated the constructive qualities of discourse, and offer an alternative methodology by which to examine eating practices.

In illustrating how eating behaviour can be variably constructed in interaction, we have highlighted some important related issuesthose of accountability, justification, and the construction of 'norms' of behaviour. Not only do these show the complexity of accounts, but they also raise questions about the methods and theories used in traditional research on eating behaviour.

\section{Conclusions}

In summary, then, we have tried to achieve two things. First, we have introduced a new approach to eating research, that using data collected from natural situations. M oreover, studying eating as it occurs in everyday life has illustrated how it may be redefined as an interactional practice rather than an individual behaviour. O ur analysis is meant to show both the possibility and the potential for studying eating in situ rather than via retrospective accounts or experimental simulations. Second, we have used these data examples to highlight some fundamental issues that are largely absent in the dominant psychological literature on eating and eating disorders.

The three issues were based around the key element of discursive construction in interaction, and on how talk about eating practices is rhetorically and collaboratively formulated. We showed some of the ways in which eating is not simply an abstract, individual activity, but is folded into social interaction and daily routine. Talking about food and eating involves constructing descriptions of food, body shape and activities, which can be used to accomplish a range of tasks (refusing and accepting, accounting for appetite and so on). The current methodology used in consumption research neglects this aspect of eating practices, relying instead mainly on studies of isolated individuals. 0 ur concern is the extent to which such research makes predictions about eating which extrapolate from studies which treat it as a decontextualized, desocialized, individual activity.

It might be argued that work of this kind is focused on questions about how eating is done as a social practice, but has little to say about the more fundamental motivational concerns of traditional eating research. It is certainly the case that discursive psychology is avoiding the factors and effects model that is typical elsewhere in psychology (for some arguments as to why, see Potter \& Edwards, in press). However, the attention to people's situated actions is attention to their issues of motive and accountability. O ur material is threaded through with concerns about why to eat or not. Thus, in a discursive psychological approach to eating 'motivations', 'causes' and 'intentions' become topics for study in themselves (Edwards, 1997; Potter, 1998). This study of the 'why' of eating as a participants' concern may have implications to psychological models of motivation on a theoretical level (for example, highlighting issues to do with 
the way taste and hunger can be interactionally negotiated) and on a methodological level (for example, highlighting some of the ways traditional measures constitute their topic).

In conclusion, it is hoped that this brief introduction to a discursive approach to food and eating will open up new avenues of research. We have tried to highlight features of eating that have been disregarded in traditional approaches. We hope that further studies of eating and interaction would start to map out the organization of food-related practices: accepting and refusing food; complimenting and criticizing; linking and separating food from issues of health, body shape and pleasure.

\section{Appendix}

\section{Transcription notation}

This was based on a J efferson-style system of transcription (see Hutchby \& Wooffitt, 1998, for a recent summary), providing the necessary detail required to analyse the conversations:

(.) A dot in a bracket indicates a pause of less than two-tenths of a second.

Colons indicate an extension of the preceeding vowel sound. The more colons there are, the greater the extent of the stretching.

(()) Words in double brackets refer to the transcriber's comments on features of the talk.

.hh A full stop before one or more ' $h$ 's indicates a speaker in-breath.

Salmon U nderlining indicates stress or emphasis in the speech.

(2.0) Numbers in brackets refer to pauses in tenths of a second.

(mine's) Words in brackets indicate the transcriber's best estimate of unclear speech.

[] Square brackets indicate the beginning and end of overlapping talk.

$=\quad$ Equal signs indicate continuous talk between speakers.

D egree signs enclose talk which is lower in volume relative to the surrounding talk.

$\uparrow \downarrow \quad$ Pointed arrows indicate a marked rising or falling in speech intonation.

$>\quad$ 'G reater than' and 'less than' signs enclose speech which is noticeably faster than the surrounding talk. When the order is reversed $(<>)$ this indicates slower speech.

\section{References}

Beach, W. A. (1996). Conversations about illness: Family preoccupations with bulimia. New Jersey: L awrence E rlbaum.

Billig, M. (1987). A rguing and thinking: A rhetorical approach to social psychology. Cambridge: Cambridge U niversity Press.

Birch, L. L. (1990). 'The control of food intake by young children: The role of learning' In E. D. Capaldi \& T. L. Powley (E ds.), Taste, experience and feeding. Washington, D C: A merican Psychological A ssociation, 116-135.

Bolles, R. C. (1990). A Functionalistic A pproach to Feeding. In E. D. Capaldi \& T. L. Powley (Eds.), Taste, experience and feeding. Washington, DC: A merican Psychological A ssociation, 3-13.

Clarke, M . G ., \& Palmer, R . L . (1983). E ating attitudes and neurotic symptoms in university students. B ritish J ournal of P sychiatry, 142, 299-304.

Davies, E., \& Furnham, A . (1986). The dieting and body shape concerns of adolescent females. Journal of Child P sychology and P sychiatry, 27(3), 417-428.

D ouglas, M ., \& Nicod, N. (1974). Taking the biscuit: The structure of British meals. New Society, 33, 744-747.

Edwards, D. (1994). Script formulations: A $n$ analysis of event descriptions in conversation. Journal of L anguage and Social P sychology, 13(3), 211-247.

E dwards, D . (1997). D iscourse and cognition. L ondon: Sage.

Edwards, D. (2000). 'The Logic of Extreme Case Formulations: Softeners, Investments and Irony'. Research on $L$ anguage and Social Interaction, 23(4), 347-373.

Edwards, D., \& Potter, J. (1992). Discursive psychology. L ondon: Sage.

E dwards, D ., \& Potter, J. (1993). L anguage and causation: A discursive action model of description and attribution. Psychological Review, 100(1), 23-41.

Goode, J. G., Curtis, K ., \& Theophano, J. (1984). M eal formats, meal cycles and menu negotiation in the maintenance of an I talian-A merican community. In M. D ouglas (E d.), Food and the social order: Studies of food and festivities in three A merican communities. N ew Y ork: R ussell Sage Foundation, 143-218.

Grogan, S., \& Wainwright, N. (1996). G rowing up in the culture of slenderness: Girls' experiences of body dissatisfaction. Women's Studies I nternational Forum, 19(6), 665-673.

H eatherton, T. F., H erman, C. P., Polivy, J ., K ing, G . A ., $\&$ M CG ree, S. T. (1988). The (mis) measurement of restraint: A $n$ analysis of conceptual and psychometric issues. Journal of A bnormal Psychology, 97(1), 19-28.

H erman, C. P., \& Polivy, J. (1980). R estrained eating. In A . J. Stunkard (E d.), O besity. Philadelphia: W. B. Saunders, 208-225. 
Hill, A . J., \& Franklin, J. A . (1998). M others, daughters and dieting: Investigating the transmission of weight control. B ritish Journal of Clinical Psychology, 37, 3-13.

Hutchby, I., \& Wooffitt, R. (1998). Conversation analysis: Principles, practices and applications. Cambridge: Polity Press.

Kennett, D. J., \& Nisbet, C. (1998). The influence of body mass index and learned resourcefulness skills on body image and lifestyle practices. Patient E ducation and Counselling, 33, 1-12.

Lupton, D. (1996). Food, the body and the self. London: Sage.

M alson, H . (1998). The thin woman: Feminism, poststructuralism and the social psychology of anorexia nervosa. L ondon: R outledge.

Mizes, J. S., \& Christiano, B. A . (1995). A ssessment of cognitive variables relevant to cognitive behavioural perspectives on anorexia nervosa and bulimia nervosa. B ehaviour Research and Therapy, 33(1), 95-105.

M onteath, S. A ., \& M cCabe, M. P. (1997). The influence of societal factors on female body image. Journal of Social Psychology, 137(6), 708-727.

$\mathrm{N}$ ash, P. (1990). The influence of nutritional awareness on consumer food choice. In M. A shwell (Ed.), Why we eat what we eat: 12th annual conference of the B ritish N utrition Foundation. L ondon: B N F , 60-78.

O chs, E ., Pontecorvo, C., \& Fasulo, A . (1996). Socialising taste. $E$ thnos, 61(1-2), 7-46.

O gden, J., \& Chanana, A . (1998). Explaining the effect of ethnic group on weight concern: Finding a role for family values. International Journal of 0 besity, 22 , 641-647.

O gden, J., \& Thomas, D. (1999). The role of familial values in understanding the impact of social class on weight concern. International J ournal of $E$ ating $D$ isorders, 25, 273-279.

Otnes, P. (1991), What do meals do? In E. L. Furst, R. Prattala, M. E kstrom, L. Holm, \& U. K jaernes (E ds.), Palatable worlds: Sociocultural food studies. O slo: Solum Forlag, 97-108.

Pomerantz, A . (1986). Extreme case formulations: A way of legitimising claims. H uman Studies, 9, 219-229.

Potter, J. (1996). Representing reality: Discourse, rhetoric and social construction. L ondon: Sage.

Potter, J. (1997). Discourse analysis as a way of analysing naturally occurring talk. In D. Silverman (Ed.), Q ualitative research: Theory, method and practice. L ondon: Sage.
Potter, J. (1998). Q ualitative and discourse analysis. In N. Schooler (Ed.), Comprehensive clinical psychology, volume 3: Research methods. A msterdam: E Isevier Science, 117-144.

Potter, J., \& Edwards, D. (in press). D iscursive social psychology. In P. Robinson \& H. Giles (Eds.), $\mathrm{H}$ andbook of language and social psychology. London: Wiley.

Potter, J., \& Wetherell, M . (1987). D iscourse and social psychology: B eyond attitudes and behaviour. L ondon: Sage.

Rodin, J. (1990). Behaviour: Its definition and measurement in relation to dietary intake. In G. H. A nderson (Ed.), Diet and behaviour: Multidisciplinary approaches. London: Springer-Verlag, 57-71.

R ogers, P. J., \& B lundell, J. E . (1990). Psychobiological bases of food choice. In M. A shwell (E d.), Why we eat what we eat: 12th annual conference of the British Nutrition Foundation. London: BNF, 31-40.

R olls, B. J ., \& H etherington, M . (1990). A behavioural scientist's perspective on the study of diet and behaviour. In G. H. A nderson ( $\mathrm{Ed}$.), Diet and behaviour: Multidisciplinary approaches. London: Springer-V erlag. 209-217.

Smith, D. (1978). K is mentally ill: The anatomy of a factual account. Sociology, 12, 23-53.

Stunkard, A . J., \& M essick, S. (1985). The three-factor eating questionnaire to measure dietary restraint, disinhibition and hunger. Journal of P sychosomatic Research, 29(1), 71-83.

Wardle, J. (1995). The assessment of obesity: Theoretical background and practical advice. Behaviour Research and Therapy, 33(1), 107-117.

Wardle, J., \& Beales, S. (1988). Control and loss of control over eating: A $n$ experimental investigation. J ournal of A bnormal Psychology, 97(1), 35-40.

Wetherell, M . (1996). Fear of fat: Interpretative repertoires and ideological dilemmas. In J. Maybin \& N. M ercer (E ds.), U sing E nglish: F rom conversation to canon. London: R outledge.

Williamson, D. A ., Barker, S. E., Bertman, L. J., \& G leaves, D. H . (1995). B ody image, body dysphoria and dietary restraint: Factor structure in non-clinical subjects. B ehaviour Research and Therapy, 33(1), 85-93.

Zdrodowski, D. (1996). E ating out: The experience of eating in public for the 'overweight' woman. Women's Studies International Forum, 19(6): 655-664. 